\author{
А.М. Кардаш. В.П. Кардаш, С.Я. Коровка
}

ГОО ВПО «Донецкий национальный медицинский университет имени М. Горького», Донецк

\title{
КЛИНИЧЕСКИЙ АНАЛИЗ ЛЕЧЕНИЯ БОЛЬНЫХ С ПОСТТРАВМАТИЧЕСКИМИ ХРОНИЧЕСКИМИ СУБДУРАЛЬНЫМИ ГЕМАТОМАМИ
}

Хроническая субдуральная гематома (ХСГ) - полиэтиологическое объемное внутричерепное кровоизлияние, располагающееся между твердой и паутинной мозговыми оболочками. Ее возникновение в основном обусловлено черепно-мозговой травмой (ЧМТ). ХСГ встречаются до $10 \%$ от общего числа перенесенных ЧМТ $[1,2]$, тогда как ЧМТ вместе с другими травматическими повреждениями занимает 3-е место в структуре общей заболеваемости, а у мужчин трудоспособного возраста - 1-е и остается одной из главных причин стойкой утраты трудоспособности населения. По наносимому суммарному медико-социальному и экономическому ущербу среди всех видов травм ЧМТ занимает первое место $[1,3,4]$, при этом количество людей со стойкой утратой трудоспособности достигает 25-30 \%. В структуре летальности от всех видов травм на долю ЧМТ приходится 30-50 \% случаев. При тяжелых формах ЧМТ с наличием внутричерепных гематом, очагов ушиба головного мозга летальность возрастает до 4185 \% [3, 4]. Работы, связанные с изучением особенностей диагностики и лечения ХСГ, остаются актуальными, так как, несмотря на успехи современной нейрохирургии, в настоящее время сохраняется высокий уровень ивалидизации и смертности преимущественно среди лиц трудоспособного возраста [5].

Развитие ХСГ приводит к местной и общей компрессии головного мозга с патоморфологическими изменениями его структуры [6, 7]. Основным морфологическим признаком, отличающим ХСГ от острых и подострых гематом, является наличие ограничительной капсулы, которая определяет особенности клинического течения и лечебной тактики заболевания [8]. Формирование капсулы при ХСГ, с одной стороны, является защитно-приспособительным неспецифическим механизмом, направленным на изоляцию ткани мозга от патологического влияния форменных элементов крови, гемосидерина и белков фибринолитической системы. С другой стороны, разрастание капсулы, окружа- ющей ХСГ, взаимосвязано с интенсивной васкуляризацией и появлением тонкостенных новообразованных сосудов, увеличением фибринолиза с разжижением кровяных сгустков внутри ХСГ [9]. Увеличение объема ХСГ происходит за счет повторных кровотечений из сосудов капсулы вследствие высокой проницаемости капилляров капсулы [10], наличия широких межэндотелиальных щелей, сосудистой транссудации, повышения онкотического градиента, связанного с местным фибринолизом [7, 9].

Выбор консервативного или оперативного метода лечения ХСГ, как правило, зависит от объема гематомы, наличия дислокационного синдрома, внутричерепной гипертензии, наличия клинической симптоматики с локальным неврологическим дефицитом, менингеальными знаками, эпилептическими приступами, нейропсихологическими нарушениями [1, 3] и др. Дислокационный синдром относится к неблагоприятным исходам ХСГ, приводит к смещению и сдавлению структур мозга и нарушению жизненно важных функций дыхания и кровообращения $[1-3,11]$. При этом ранняя клиническая диагностика ХСГ существенно затруднена вследствие стертой клинической картины дислокационных признаков.

Целью работы явилось проведение клинического анализа результатов диагностики, лечения и развития рецидивов посттравматической $\mathrm{XCГ.}$

\section{МАТЕРИАЛ И МЕТОДЫ}

Проанализированы истории болезней 246 человек, которые находились на лечении в нейрохирургической клинике Донецкого клинического территориального медицинского объединения в период 2015-2020 гг. с диагнозом ХСГ после ЧМТ. Среди больных было 197 (80,1 \%) мужчин и 49 (19,9\%) женщин в возрасте от 25 до

(c) А.М. Кардаш. В.П. Кардаш, С.Я. Коровка, 2020 (c) Университетская Клиника, 2020 
55 лет (средний возраст (M $\pm \mathrm{SD}) 41,45 \pm 7,54$ лет). У 128 (52,0\%) больных ХГС возникла в результате легкой ЧМТ, а у 98 (39,8 \%) - ЧМТ средней степени тяжести. Отсутствие указаний на ЧМТ в анамнезе ХСГ отмечено у 20 (8,1\%) пациентов. Все больные были распределены на 3 возрастные группы: 25-35 лет - 47 (19,1 \%) больных, 36-45 лет - 129 (52,4 \%), 46-55 лет - 70 (28,5 \%). Пациенты с ХСГ обращались за медпомощью в период от 3 недель до 4 месяцев после произошедшей ЧМТ. Среди обратившихся за медпомощью 36 пациентов (14,6 \%) не могли четко указать факт и сроки ЧМТ, что объяснялось состоянием алкогольного опьянения во время травмы. У остальных больных первые клинические признаки ХСГ проявлялись в следующие сроки после ЧМТ: через 3-4 недели у 52 (24,8 \%); через 1-2 месяца у 75 (35,7 \%); через 3-4 месяца у 83 (39,5 \%) пациентов.

Всем пациентам, поступившим в отделение, проводили комплексное общеклиническое обследование, неврологический осмотр, лабораторные исследования крови и мочи, компьютерную томографию (КТ) головного мозга.

\section{РЕЗУЛЬТАТЫ И ОБСУЖДЕНИЕ}

Течение ХСГ характеризовалось вариабельностью клинических признаков и было представлено следующими синдромами: церебральноочаговым - у 148 (60,2 \%), эпилептическим - у $44(17,9 \%)$ и гипертензионно-гидроцефальным - у 54 (21,9\%) пациентов.

Общемозговую симптоматику расценивали как умеренно выраженную при постоянной головной боли и тошноте; как выраженную - при сильной нестерпимой головной боли и постоянной рвоте. При оценке менингеального синдрома учитывали наличие светобоязни, ригидности мышц затылка, положительного симптома Кернига.

Объемы ХСГ составляли от 5 см3 до 150 см3. Объем гематомы - 5-10 см3, который не требовал хирургического лечения, имел место у 48 (19,5\%) больных. У 34 (17,2\%) больных обнаруживали гематомы объемом 10-50 см3, у 55 (27,8 \%) - 50-100 см3 и у 109 (55,0\%) - свыше 100 см3. При двустороннем расположении ХСГ общий объем гематом достигал 200-350 см3. ХСГ имели лобно-теменно-височную локализацию у 185 (75,2 \%) пациентов, лобно-височную у 23 (9,3 \%), лобно-теменную у 8 (3,3 \%), теменнозатылочную у 14 (5,7 \%), занимающие все полушарие - у 16 (6,5 \%) пациентов.

Консервативное лечение проводили при ХСГ малого объема и удовлетворительном общем состоянии с минимальной неврологической симптоматикой (небольшие головные боли, слабо- выраженные менингеальные симптомы и др.). При консервативном лечении назначали аналгетики, препараты интенсивной противоотечной терапии, улучшающие реологические свойства крови, нейропротекторы, антиоксиданты, антигипоксанты, витаминотерапию.

У 198 (80,5 \%) человек проведено хирургическое лечение. Показания к хирургическому лечению и выбору оперативного вмешательства определяли в зависимости от предоперационного состояния пациента, объема и локализации ХСГ, а также выраженности дислокационного синдрома и перифокального отека [12]. Применяли различные оперативные методы лечения ХСГ: удаление ХСГ с помощью костнопластической трепанации. Предпочтение отдавали малоинвазивным вмешательствам, таким как дренирование гематомы из фрезевых отверстий $[13,14,15,16]$. Для этого в кости над очагом гематомы фрезой с ограничителем просверливали под углом 45 градусов к черепу два фрезевых отверстия, одновременно вскрывали твёрдую мозговую оболочку и подлежащую капсулу гематомы. Вскрытие капсулы производили с использованием небольшого разреза, достаточного для введения дренажа. Сосуды твердой мозговой оболочки и края разреза капсулы тщательно коагулировали. Отсосом удаляли содержимое гематомы. Через второе фрезевое отверстие, расположенное дистальнее, полость гематомы промывали подогретым до 370С физиологическим раствором. В полость гематомы вводили эластичные дренажные трубки, которые фиксировали к коже фрезевого отверстия. В послеоперационном периоде полость ХСГ промывали с целью активного удаления крови, предупреждения повторных кровотечений из капсулы гематомы и предупреждения рецидивирования ХСГ. При эффективном лечении происходило постепенное расправление мозга, снижался риск развития послеоперационного постдекомпрессионного отека мозга, интраоперационной пневмоцефалии, гнойно-воспалительных интракраниальных осложнений и др. В 4 (1,6 \%) наблюдениях из-за обызвествления гематомы, наличия трабекул, свидетельствующих о мнокамерности гематомы, выполнили костно-пластическую трепанацию черепа.

Результаты хирургического лечения по шкале исходов Глазго (Glasgow Outcome Scale) pacпределились следующим образом: с хорошим восстановлением пациента - 213 (86,6 \%) случаев, с умеренной инвалидизацией - 23 (9,4\%), с тяжелой инвалидизацией - 7 (2,8 \%), с летальным исходом - 3 (1,2 \%) случая. Летальные исходы и последствия, приведшие к тяжелой инвалидизации пациентов, были обусловлены их 
тяжелым состоянием на момент обращения пациентов за медпомощью, которое было оценено по шкале комы Глазго (ШКГ) в 3-6 баллов.

Несмотря на то что многочисленные нейрохирургические центры и школы ближнего и дальнего зарубежья выступают за миниинвазивные оперативные вмешательства и продолжают совершенствовать методики их выполнения $[13,14]$, существует мнение $[5,10]$ о необходимости выполнения костно-пластической трепанации с иссечением капсулы гематомы. Такой подход объясняется желанием радикального устранения причин развития часто встречающихся послеоперационных осложнений и рецидивов ХСГ. В то же время установлено, что развитие осложнений и рецидивов ХСГ встречается как при применении миниинвазивных операций с одним или двумя фрезевыми отверстиями, так и при выполнении костно-пластической трепанации в 18-22 \% и 25-33 \% случаев соответственно [15].

В качестве примера приводим клинический разбор двух пациентов.

Больной А. 52-х лет поступил 10.09.2020 г. в нейрохирургическую клинику ДоКТМО с диагнозом ХСГ. При поступлении предъявлял жалобы на головную боль, головокружение при ходьбе, слабость, усиливающуюся к вечеру и после небольшой физической нагрузки. Считает себя больным в течение 1-го месяца после травмы головного мозга в результате удара крышкой люка при входе в подвал. После травмы возникла головная боль, которая стала усиливаться в последние 2 недели. Неврологический осмотр показал: сознание ясное, ШКГ - 15 баллов, отмечены тревожно-депрессивные проявления. Размеры зрачков справа и слева одинаковые, движения глазных яблок сохранены в полном объеме. Определяется сла- бость конвергенции с 2 сторон. Диагностирован слабо выраженный правосторонний гемипарез. Патологических рефлексов нет. Менингеальных симптомов нет. Расстройств чувствительности не выявлено. Произведена КТ головного мозга: обнаружены КТпризнаки ХСГ справа (рис. 1.). 12.09.2020 г. выполнена операция с удалением гематомы через 2 фрезевых отверстия с декомпрессией головного мозга и дренированием полости гематомы в течение 2 суток после операции. В послеоперационном периоде состояние пациента стабилизировалась. На контрольном КТобследовании 18.09.2020 г. над правым полушарием визуализируется остаточная полость, частично вызывающая компрессию, желудочковая система мозга имеет тенденцию к восстановлению. Больной выписан в удовлетворительном состоянии с регрессом неврологических нарушений.

Далее представлен клинический случай рецидивирующего течения ХСГ.

Пациент Н. 50 лет поступил в нейрохирургическое отделение ДоКТМО 01.10.2020 г. с жалобами на периодические головные боли, шум в ушах, головокружение при ходьбе, быструю утомляемость, тошноту, рвоту, общую слабость. Из анамнеза известно, что в мае 2020 г. дома получил ЧМТ легкой степени при автомобильной травме, за медпомощью не обращался. Через месяц больного стали беспокоить постоянные головные боли, прием аналгетиков был неэффективен. После обследования 19.06.2020 г. обнаружены КТ-признаки ХСГ слева. 22.06.2020 г. произведено удаление гематомы с наложением 2 фрезевых отверстий и дренированием полости гематомы. На 10-е сутки после операции больной был выписан в удовлетворительном состоянии на амбулаторное лечение. Со слов больного, через 2-2,5 месяца после выписки он стал отмечать ухудшение состояния с появлением вышеуказанных жалоб. При осмотре пациента: сознание ясное, ШКГ - 15 баллов, частично дезо-

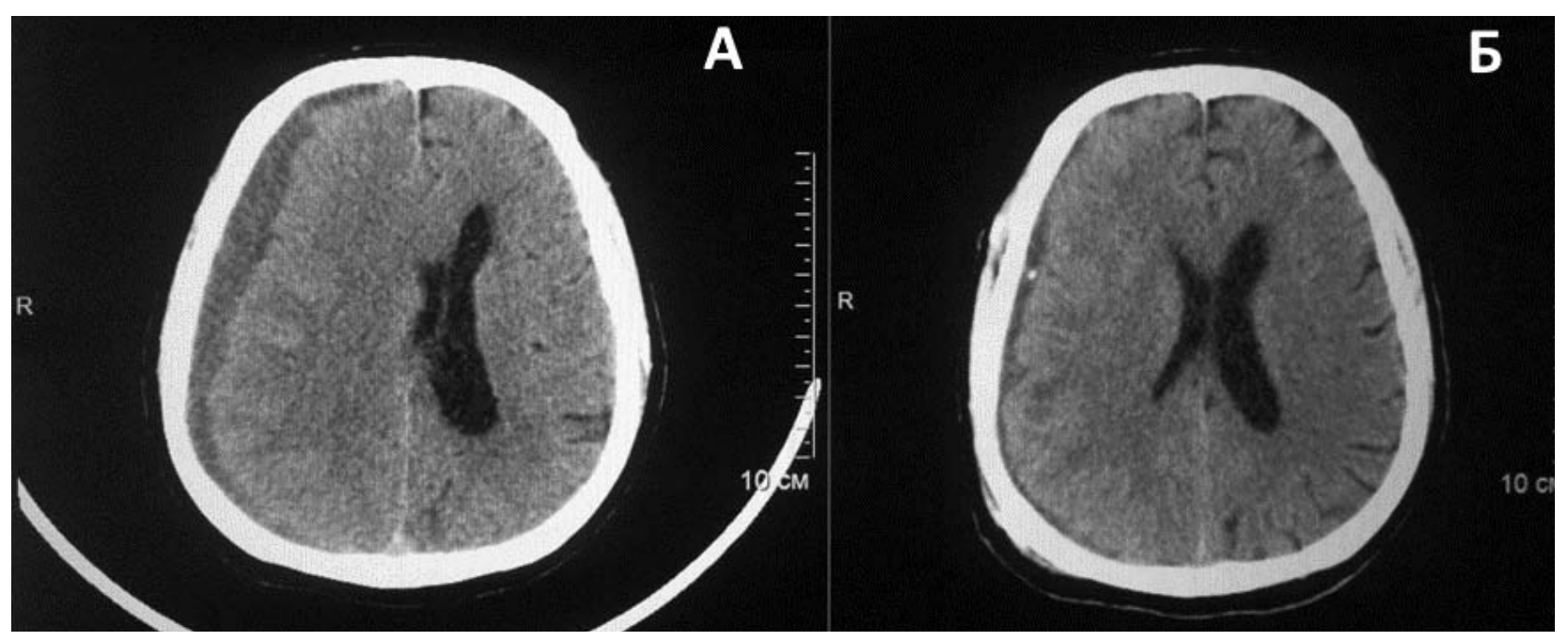

Рис. 1. Больной А. Результаты КТ обозначение на рисунке: А - хроническая субдуральная гематома справа, Б - контрольное исследование на 7-е сутки после операции. 


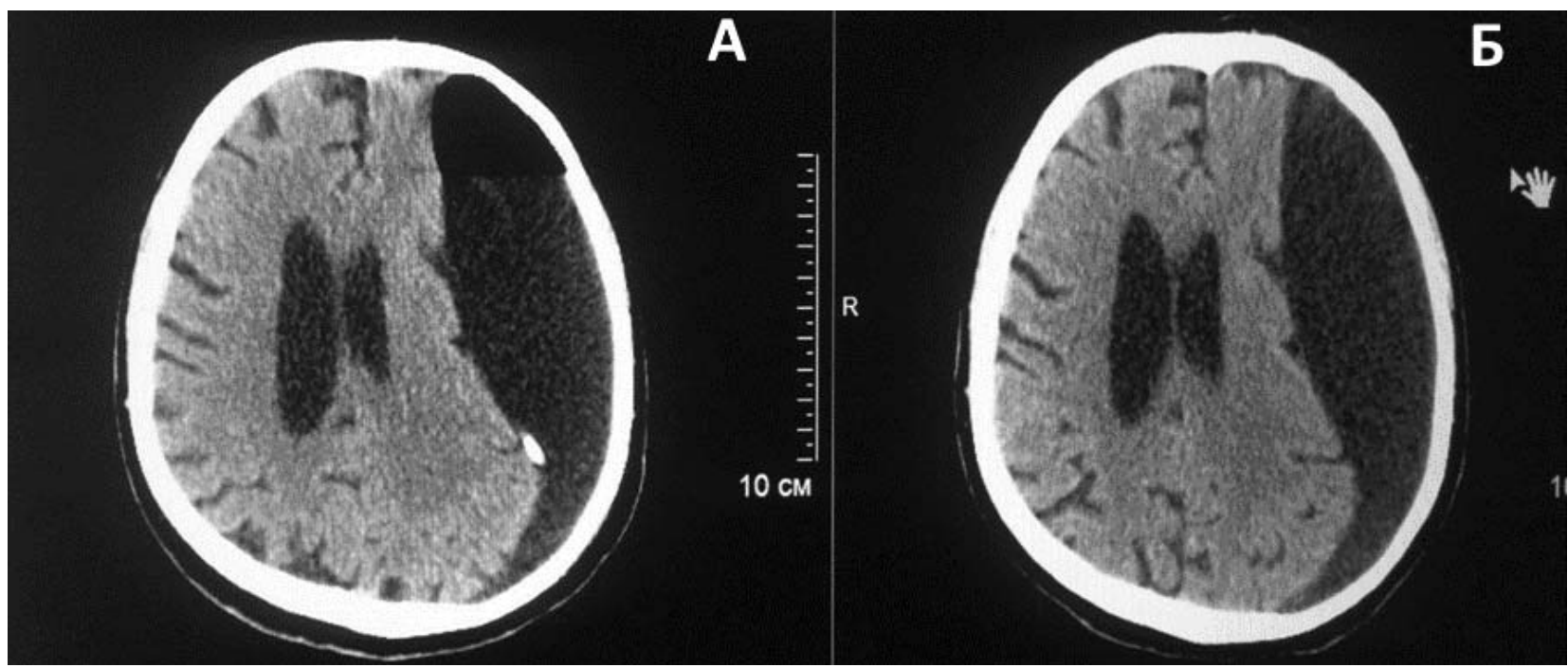

Рис. 2. Пациент Н. Результаты КТ обозначение на рисунке: А - хроническая субдуральная гематома слева, Б исследование через 3 месяца после операции: рецидив хронической субдуральной гематомы.

риентирован в месте и времени, снижена критика к собственному состоянию. Слабость конвергенции с 2 сторон, умеренный правосторонний гемипарез, патологических рефлексов нет, менингеальных симптомов нет, расстройств чувствительности не выявлено. На КТ: признаки ХСГ слева с выраженным перифокальным отеком и смещением срединных структур головного мозга на 12 мм. 05.10.2020 г. выполнена операция удаления гематомы с применением фрезевых отверстий и дренированием полости гематомы, которое было продлено до 5 суток с целью контроля за повторным кровоизлиянием. Больной выписан на 21-е сутки. Общемозговые симптомы, психоневрологические нарушения не выявлены. На контрольной
КТ над левым полушарием определялась остаточная полость без признаков компрессии и смещения желудочковой системы (рис. 2.).

\section{З АКЛЮЧЕНИЕ}

Значительный полиморфизм причин, ведущих к возникновению рецидивов ХСГ и сроков их формирования в послеоперационном периоде, требует проведения адекватного клиникопатогенетического анализа с целью разработки системы профилактических мероприятий и обоснованного выбора эффективных методов диагностики и лечения рецидивирования ХСГ.

\section{А.М. Кардаш, В.П. Кардаш, С.Я. Коровка}

ГОО ВПО «Донецкий национальный медицинский университет имени М. Горького», Донецк

\section{КЛИНИЧЕСКИЙ АНАЛИЗ ЛЕЧЕНИЯ БОЛЬНЫХ С ПОСТТРАВМАТИЧЕСКИМИ ХРОНИЧЕСКИМИ СУБДУРАЛЬНЫМИ ГЕМАТОМАМИ}

Актульность работ, посвященных изучению клинических особенностей посттравматических хронических субдуральных гематом (ХСГ), определяется сохраняющимся высоким уровнем ивалидизации и смертности среди лиц трудоспособного возраста.

Проведен анализ результатов диагностики и лечения 246 пациентов с посттравматическими ХСГ по данным нейрохирургической клиники Донецкого клинического территориального медицинского объединения за 2015-2020 гг. Представлены данные об особенностях клинического течения и методах консервативного и хирургического лечения ХСГ с при- менением миниинвазивных оперативных технологий. Значительная вариабельность причин, ведущих к возникновению рецидивов ХСГ и сроков их формирования в послеоперационном периоде, требует проведения адекватного клинико-патогенетического анализа с целью разработки системы профилактических мероприятий и обоснованного выбора эффективных методов диагностики и лечения рецидивирования ХСГ.

Ключевые слова: черепно-мозговая травма, хроническая субдуральная гематома, рецидивирующая субдуральная гематома 


\section{A.M. Kardash, V.P. Kardash, S.Ya. Korovka}

\section{SEI HPE «M. Gorky Donetsk National Medical University», Donetsk}

\section{CLINICAL ANALYSIS OF TREATMENT PATIENTS WITH POSTTRAUMATIC CHRONIC SUBDURAL HEMATOMAS}

The relevance of scientific works devoted to the study of the clinical features of post-traumatic chronic subdural hematomas (CSDH) is determined by the continuing high level of invalidization and mortality among people of working age.

The analysis of the results of diagnostics and treatment of 246 patients with post-traumatic CSDH was carried out according to the data of the neurosurgical clinic of the Donetsk clinical territorial medical association for 2015-2020. The data on the features of the clinical course and methods of conservative and surgical treatment of
CSDH using minimally invasive surgical technologies are presented. The significant variability of the causes leading to the occurrence of CSDH relapses and the timing of their formation in the postoperative period require an adequate clinical and pathogenetic analysis in order to develop a system of preventive measures and a reasonable choice of effective methods for the diagnosis and treatment of CSDH recurrence.

Key words: traumatic brain injury, chronic subdural hematoma, recurrent subdural hematoma

\section{ЛИТЕРАТУРА}

1. Лихтерман Л.Б. Классификация черепно-мозговой травмы. Часть III. Слагаемые диагноза ЧМТ и принципы его построения. Судебная медицина. 2015; 4: 3440.

2. Faul M, Coronado V. Epidemiology of traumatic brain injury. Handbook of Clin Neurol. 2015; 127: 3-13.

3. Крылов В.В., Петриков С.С., Талыпов А.Э., Пурас Ю.В., Солодов А.А., Левченко О.В., Григорьева Е.В., Кордонский А.Ю. Современные принципы хирургии тяжелой черепно-мозговой травмы. Журнал им. Н.В. Склифосовского «Неотложная медицинская помощь». 2013; (4): 39-47.

4. Лекции по черепно-мозговой травме: Учебное пособие. Под ред. Крылова В.В. М.: Медицина; 2010. 320.

5. Полховский А.А. Ранняя диагностика, особенности течения и лечения хронических субдуральных гематом у больных пожилого и старческого возрасти: автореф. дис. .... канд. мед. наук. Москва; 2007. 26.

6. Лихтерман Л.Б., Потапов А.А., Кравчук А.Д. Хроническая субдуральная гематома. Consilium Medicum. 2008; 10 (12): 71-81.

7. Werner C, Engelhard K. Pathophysiology of traumatic brain injury. British J. Anaesth. 2007; 99: 4-9.

8. Lantigua H., Ortega-Gutierrez S., Schmidt J.M., Lee K., Babjatia N., Agarwal S., Claassen J., Sonnolly E.S., Mayer S.A. Subarachnoid hemorrhage: who dies, and why? Crit Care. 2015; 19 (1): 309-319.

9. Крылов В.В., Буров С.А., Галанкина И.Е., Дашьян В.Г. Метод локального фибринолиза в хирургии травматических внутричерепных гематом. Вопросы нейрохирургии им. Н.Н. Бурденко. 2006; 3: 23-29.

10. Крылов В.В., Талыпов А.Э., Пурас Ю.В., Ефременко С.В. Вторичные факторы повреждений головного мозга при черепно-мозговой травме. Росмед. журн. 2009; 3: $23-28$.

11. Guresir E. Schuss P., Vater H., Raabe A., Seifert V., Beck J. Decompressive craniectomy in subarachnoid hemorrhage. Neurosurg Focus. 2009; 26 (6): E4.

12. Zoerle T., Lombardo A., Colombo A., Longhi L., Zanier E.R., Rampini P. Stocchetti N. Intracranial pressure after subarachnoid hemorrhage. Crit Care Med. 2015; 43 (1): 168-76.

13. Шиголев Ю.С., Цехановский Г.Б. Лечение хронических субдуральных гематом в аспекте современных малоинвазивных методик. Материалы II Российскоамериканской научно-практической конференции. Москва; 2003: 188-190.

14. Horn E.M., Feiz-Erfan I., Bristol R.E., Spetzler R.F., Harrington T.R.: Beside twist drill craniostomy for chronic subdural hematoma: a comparative study. Surg. Neurol.

\section{REFERENCES}

1. Likhterman L.B. Klassifikatsiya cherepno-mozgovoy travmy. Chast' III. Slagaemye diagnoza ChMT i printsipy ego postroeniya. Sudebnaya meditsina. 2015; 4: 34-40 (in Russian).

2. Faul M, Coronado V. Epidemiology of traumatic brain injury. Handbook of Clin Neurol. 2015; 127: 3-13 (in Russian).

3. Krylov V.V., Petrikov S.S., Talypov A.E., Puras Yu.V., Solodov A.A., Levchenko O.V., Grigor'eva E.V., Kordonskiy A.Yu. Sovremennye printsipy khirurgii tyazheloy cherepno-mozgovoy travmy. Zhurnal im. N.V. Sklifosovskogo «Neotlozhnaya meditsinskaya pomoshch'». 2013; (4): 3947 (in Russian).

4. Lektsii po cherepno-mozgovoy travme: Uchebnoe posobie. Pod red. Krylova V.V. M.: Meditsina; 2010. 320 (in Russian).

5. Polkhovskiy A.A. Rannyaya diagnostika, osobennosti techeniya i lecheniya khronicheskikh subdural'nykh gematom u bol'nykh pozhilogo i starcheskogo vozrasti: avtoref. dis. ... kand. med. nauk. Moskva; 2007. 26 (in Russian).

6. Likhterman L.B., Potapov A.A., Kravchuk A.D. Khronicheskaya subdural'naya gematoma. Consilium Medicum. 2008; 10 (12): 71-81 (in Russian).

7. Werner C, Engelhard K. Pathophysiology of traumatic brain injury. British J. Anaesth. 2007; 99: 4-9.

8. Lantigua H., Ortega-Gutierrez S., Schmidt J.M., Lee K., Babjatia N., Agarwal S., Claassen J., Sonnolly E.S., Mayer S.A. Subarachnoid hemorrhage: who dies, and why? Crit Care. 2015; 19 (1): 309-319.

9. Krylov V.V., Burov S.A., Galankina I.E., Dash'yan V.G. Metod lokal'nogo fibrinoliza $\mathrm{v}$ khirurgii travmaticheskikh vnutricherepnykh gematom. Voprosy neyrokhirurgii im. N.N. Burdenko. 2006; 3: 23-29 (in Russian).

10. Krylov V.V., Talypov A.E., Puras Yu.V., Efremenko S.V. Vtorichnye faktory povrezhdeniy golovnogo mozga pri cherepno-mozgovoy travme. Rosmed. zhurn. 2009; 3: 2328 (in Russian).

11. Guresir E. Schuss P., Vater H., Raabe A., Seifert V., Beck J. Decompressive craniectomy in subarachnoid hemorrhage. Neurosurg Focus. 2009; 26 (6): E4.

12. Zoerle T., Lombardo A., Colombo A., Longhi L., Zanier E.R., Rampini P. Stocchetti N. Intracranial pressure after subarachnoid hemorrhage. Crit Care Med. 2015; 43 (1): 168-76.

13. Shchigolev Yu.S., Tsekhanovskiy G.B. Lechenie khronicheskikh subdural'nykh gematom v aspekte sovremennykh maloinvazivnykh metodik. Materialy II Rossiyskoamerikanskoy nauchno-prakticheskoy konferentsii. Moskva; 2003: 188-190 (in Russian).

14. Horn E.M., Feiz-Erfan I., Bristol R.E., Spetzler R.F., Harrington T.R.: Beside twist drill craniostomy for chronic 
2006; 65: 150-154.

15. Weigel R., Schmiedek P., Krauss J.K.: Outcome of contemporary surgery for chronic subdural haematoma: evidence based review. J. Neurol. Neurosurg. Psychiatry. 2003; 74: 937-943.

16. Kolias A.G., Chari A, Santarius T., Hutchinson P.J. Chronic subdural haematoma: modern management and emerging therapies. Nat Rev Neurol. 2014; 10: 570-578. subdural hematoma: a comparative study. Surg. Neurol. 2006; 65: 150-154.

15. Weigel R., Schmiedek P., Krauss J.K.: Outcome of contemporary surgery for chronic subdural haematoma: evidence based review. J. Neurol. Neurosurg. Psychiatry. 2003; 74: 937-943.

16. Kolias A.G., Chari A., Santarius T., Hutchinson P.J. Chronic subdural haematoma: modern management and emerging therapies. Nat Rev Neurol. 2014; 10: 570-578. 